\title{
Severe disability and its prevalence and causes in northwestern Ethiopia: evidence from Dabat district of Amhara National Regional State. A community based cross-sectional study
}

Solomon Mekonnen Abebe ( $\nabla$ solomekonnen@yahoo.com )

University of Gondar College of Medicine and Health Sciences

Mikyas Abera

University of Gondar College of Social Sciences and Humanities

Ansha Nega

Addis Ababa University

Zemichel Gizaw

University of Gondar College of Medicine and Health Sciences

Mulugeta Bayisa

University of Gondar College of Medicine and Health Sciences

Solomon Fasika

University of Gondar College of Medicine and Health Sciences

Molalign Belay

University of Gondar College of Social Sciences and Humanities

Abel Fekadu

University of Gondar College of Medicine and Health Sciences

Wondwossen Wakene

University of Gondar School of Law

\section{Research article}

Keywords: disability, PwDs, DHSS, household survey, northwestern Ethiopia

Posted Date: January 11th, 2021

DOI: https://doi.org/10.21203/rs.3.rs-18602/v5

License: (c) (i) This work is licensed under a Creative Commons Attribution 4.0 International License. Read Full License 


\section{Abstract}

Background: Disability is the social outcome of unfavorable interactions between individuals' impairments, on the one hand, and inaccessible physical spaces, disenabling cultural environment and negative attitudes towards disability and persons with disabilities, on the other. Despite the fact that it directly affects $15 \%$ of Ethiopians as well as families and communities, policy-relevant studies on disability and the conditions of persons with disabilities are lacking. The Dabat Demographic Health Surveillance System (DHSS) was established to collect vital statistics in Dabat district, Amhara region. But it did not collect data on disability types, causes and community responses. With this drawback in DHSS, this study aimed at assessing the prevalence, types and major causes of severe disability in Dabat district.

Method: A community-based cross-sectional study design was employed and covered 17,000 households residing in 13 Kebeles of Dabat district. The study was conducted in 2018 utilizing the modified 12-item World Health Organization's Disability Assessment Schedule (WHODAS 2.0) and 7-item WHO Minimal Generic Set of Domains of Functioning and Health to collect data on disability in the district. The data were organized and presented as frequencies and percentages in table and figures. Relevant variables were used to construct a logit model that predicts the likelihood of disability whereby P-value $<0.05$ was considered as statistically significant.

Results: This study found that the overall prevalence of disability in Dabat district was 2.14\% [95\% Cl: 2.03, 2.24]. About $8.3 \%$ of households reported at least one member with disability. Visual impairment was the most commonly reported impairment (51\%) while $8.19 \%$ had multiple impairments. Eighty-three percent of immediate the causes of disability were modifiable - specifically, illness (36.93\%), injury (17.81\%), and congenital (10.86\%). The aged $[A O R=1.0 ; 95 \% \mathrm{Cl}: 1.03,1.04]$, those unable to read or write illiterate [AOR=1.57; $1.15,2.14]$, the unmarried/single $[\mathrm{AOR}=1.39 ; 95 \% \mathrm{Cl}: 185,2.47]$ and the separated $[\mathrm{AOR}=2.78 ; 95 \% \mathrm{Cl}: 4.14,6.19]$ were more likely to risk disability in the population.

Conclusion: This study reported an increased likelihood of impairment among those with advanced ages. The proportion of households with PwDs was also high. While most disabilities were visual, there were significant numbers with mobility impairments and hard of hearing. Most school-age PwDs did not complete secondary education, while employment was significantly limited. The findings indicated that most causes of disability were reversible if impairments were screened or identified early and preventive or medical treatments were sought. Without undermining the role of specialized medical treatments, this study underlines the significance of early screening and preventive community interventions through CBR programs and rehabilitation workers in lowering disability rates in the district.

\section{Background}

With multiple types and causes, impairment or disability can affect any person at some point in life, temporarily or permanently. Though impairment and disability had been used interchangeably well into the 1970 s, disability movement espoused a social model that distinguished between the two i.e., impairment as a function of the condition the body or mind, and disability as an undesirable "outcome of an oppressive relationship between people with impairments and the rest of society" (31). This powerful distinction between the body and the society/culture, impairment and disability has helped the disability movement towards the advancement of the rights of persons with disabilities (PwDs). 
But these achievements of the social model came at the cost of, some writers (e.g., Hughes and Paterson 1997) argued, emptying disability from the rich personal experiences of impairment, which made disability inadequate as a concept in postmodern identity politics centered on the body as a contested cultural terrain (32). Hughes and Paterson (1997) proposed not only to bring back the body/impairment experience into the cultural, symbolic space but also account for the multiple, individualized representations of pain and the oppressive societal/environmental factors. If the body enters the cultural realm in disability studies and movement, they argued, it can become a powerful 'emancipatory' concept.

This study drew on the WHO-ICF definition of disability whereby a person is considered disabled if and when his/her activity performances in his/her usual environment are limited in nature, function, or quality. This definition shifts the focus from individual factors measured in terms of medical or health indicators to broader factors that include health, education, social relationships and cultural participation. It treated disability in contrast to full functionality and both are "conceived as a dynamic interaction between health conditions (diseases, disorders, injuries, traumas, etc.) and contextual factors." (33) In a way, such a definition draws on the complementary conceptualization of disability - with their own variations, of course - in the social model and the capabilities framework i.e., not only in understanding disability in terms of social/environmental barriers to equal opportunities and resources but also in identifying discrimination and oppression as central to its characterization (31). As such, this study recognizes all physical or learning and intellectual impairments that cause limited social functionality, opportunities and autonomy that are inconsistent with human dignity, equality and inclusion as disability.

Disability statistics, services and barriers. Using the definition of disability adopted in this study, the WHO and the World Bank (WB) estimated that about $80 \%$ of the global 1 billion persons with disabilities (PwDs) currently live in low and middle-income countries (1). In most of these countries, especially on the African continent, community attitude towards disability and persons with disabilities are less than penchant and socioeconomic support and rehabilitation services are poor or non-existent $(40,41)$. These challenges persisted, and the numbers of PwDs are increasing - both globally and in developing countries - due to population growth, man-made and natural disasters, war, accidents and aging.

In Ethiopia, data on the prevalence of disability is highly fragmented, or sometimes misleading and contradictory. For example, the 2007 Population and Housing Census reported the prevalence of disability to be $1.2 \%$. Conversely, WHO estimates the national prevalence of disability in Ethiopia around 17\% (1) The in-congruence between the two disability statistics could be due to several factors. The Census report was based on self-identification of household heads and members as being disabled or not, which generally underestimates prevalence rates due to stereotypes and stigma attached to disability (33). Furthermore, statistics on disability varies "according to the purpose and application of the data, the conception of disability, the aspects of disability examined, the definitions, question design, reporting sources, data collection methods, and expectations of functioning" $(1)$. Many $(34,35)$ have reported skepticism about the Census statistics on disability in Ethiopia that could have been affected by "under-reporting, the way the Census questions were formulated, lack of disability awareness among enumerators and data managers and use of a narrow definition of disability". In fact, there are reports that PwDs tend to avoid reporting their conditions due to negative community attitude towards disability and PwDs, which are prevalent in Ethiopia $(34,35,39)$. In similar contexts, studies had identified institutional and cultural factors such as cost of treatment and stigma where there is significant underreporting (38). These reports show how Census reports actually underline the unreliability of statistics on PwDs in Ethiopia. 
The significance of reliable disability statistics cannot be overstated. Having reliable statistics on disability informs better, policy making, planning and programming centered on inclusive and sustainable development. Data on the level of functioning in the population and the need for social and rehabilitation services will guide interventions to promote the equalization of opportunity and access to social resources such as education and health for PwDs. In recent years, national and global actors have used disability statistics to push the issue of disability to the center and front of policies, programming and service provision to ensure the effective inclusion of PwDs in development.

Empirical evidence on causes and impacts of disability on people are also relevant to prevention and rehabilitation policy making and programming. In Africa, studies identified the major causes of disability as communicable diseases, war, accidents, and inadequate prenatal and neonatal health-care services $(36,37)$. It has been reiterated that disability is strongly linked to underlying and basic problems of poverty, poor nutrition and restricted access to basic services such as health and schooling. These factors are also relevant to the Ethiopian context where the list of causes/factors include low standard of living, malnutrition, natural and man-made disasters, accidents, infectious and non-infectious diseases, intermittent wars and violence.

The challenges PwDs face - as we have noted above - emanate from unfavorable relationships between their impairments and their social environment. The outcomes of disability have more to do with the way disability is perceived and treated by communities than the degree and type of physical impairments. African communities harbor misconceptions that deter the inclusion of PwDs and expose them to debilitating stigma. For instance, traditional/rural African communities attribute impairments to such factors as supernatural forces - curse, demonic possession or wrath of god for a family's mischiefs $(42,43)$. This scenario has, in turn, led to PwDs poor mental health and well-being.

But PwDs do not form a homogenous group. Despite inconsistencies, the literature and statistical reports on disability in Ethiopia identify mobility, visual and hearing impairments as the top-three most prevalent forms of disabilities, in that order. The prevalence and types have also been reported to be similar in North Gondar Administrative Zone of the Amhara National Regional State (ANRS), Ethiopia.

In addition to difference in the type of impairments (e.g., physical, psycho-social, sensory, intellectual, neurological), PwDs live in a variety of contexts with different intersecting identities. This includes gender, age, education status, employment and economic status, and, geographical location. How these contexts and different characteristics intersect lead to very different experiences of disability [15]. In Ethiopia, for instance, about $46 \%$ of PwDs are women who carry the double burden of stigma, discrimination and other challenges due to patriarchy and misgivings about disability. Age is also a factor whereby children with disabilities (CwDs) are less likely to attend schooling or access healthcare services leaving them vulnerable to poverty and poor health that substantially reduce their quality of life $[17,18]$. As a group, without underplaying these variations within however, PwDs are still among the most disadvantaged segment of the society.

With the understanding that disability statistics and surveillance are necessary to assess and examine trends and conditions of PwDs to inform policies, strategies and programming, this study aims at filling the existing knowledge gap on disability, mainly severe disability, its prevalence, types and causes in Ethiopia, specifically northwestern Ethiopia, and promote the effectiveness of services and interventions to meet the challenges of PwDs. It builds on the Dabat Health Surveillance System (DHSS) that the University of Gondar (UoG) established in 1995 to collect, organized and disseminate regular and up-to-date information on vital statistics - birth, death, migration and pregnancy - in Dabat district, northwestern Ethiopia. The justification for the DHSS lay in the 
relevance of up-to-date information on population to policy, planning and programming in all levels and sectors. But it included only one question on disability - "Are there members in the household with disability?" - which did not produce detailed information on degree, types and causes of disability.. It is against this backdrop that this study aims at assessing the prevalence, types and causes of severe disability in Dabat district employing a disability measurement tool adapted from WHO Disability Assessment Schedule (WHODAS

\section{Methods}

\section{Study Area}

This paper discusses the prevalence, types and major causes of severe disability in Dabat district, northwestern Ethiopia - the district wherefrom DHSS collects longitudinal study. Dabat town is the administrative center of Dabat district and it is located $60 \mathrm{kms}$ northwest of Gondar city. The Dabat district covers $1,199.15 \mathrm{~km}^{2}$ area and has an estimated population of 168,331 (male/female: 50\%) (CSA 2013). It is administratively organized under 5 urban and 27 rural Kebeles - the smallest administrative unit in Ethiopia - with altitudes ranging between 1000 and 3000 meters above sea level (Dabat Rural Project Statistics, 2015).

The district has 29 health posts, 3 health stations and 2 health centers. UoG established DHSS in 1995 to collect demographic, social and health data in 13 Kebeles (9 rural and 4 urban) of 32 Kebeles of the district. According to the 2014 Re-census Baseline Survey, DHSS collects data on 17,000 households, with 72,000 inhabitants, semiannually.

\section{Study Design}

To identify the prevalence, types and causes of severe disability at Dabat district, the study used a communitybased cross-sectional design. Data were collected by enumerators and supervisors who visited all households in the DHSS catchment area and interviewed household heads between January and June 2018. This survey makes part of the add-on cross-sectional survey launched in 2016 to specifically address the gap in the DHSS data on the prevalence, types and causes of disability.

\section{Study Population}

This study covered members and permanent residents of 17,000 households in 13 Kebeles of Dabat district. Thirtythree trained and experienced enumerators, overseen by nine supervisors, interviewed household heads to collect data on incidences, types and causes of disability among all household members and permanent residents.

Though this study collected data on the same population as the DHSS, it uniquely focused on collecting data on disability through an adapted measurement tool from WHODAS 2.0 and ICF.

\section{Sample size and sampling procedures}

Theoretically, this study included all members and permanent residents of 17,000 households as well as those on the streets in the 13 Kebeles within the Dabat district. Actually, there were no street dwellers in the district and the study excluded those who were not permanent residents (less than 6 months, as per the CSA definition of 'household members') at the time of data collection. 


\section{Data collection: tools and procedure}

The survey employed a structured and pre-tested questionnaire adapted from WHODAS-2.0and ICF. WHODAS-2.0 is a standardized and validated tool to assess health and disability status both at individual and community levels, and across cultures. As a generic tool, it assesses disability induced limitations on activity and participation both in community and clinical set-up. Furthermore, it has been fruitfully deployed to measure the effectiveness of disability interventions. The study applied WHODAS 2.0 when interviewing respondents above the age of 18 . The survey questionnaire specifically adapted items from WHODAS-2.0 that measure the six domains of disability: learning and intellectual, mobility, self-care, getting along, life activities and participation.

The ICF - children and youth version (ICF-CY) - was used to assess disability, activity limitations and other outcomes among population under 18 years of age.

The questionnaire was first designed in English and then translated to Amharic - the official language of Ethiopia and spoken by residents of the Dabat district. The adaptation and validation of the questionnaire to the local context involved piloting, which was conducted in one Kebele - later excluded from the survey - and provided information to assess the relevance and appropriateness of its items and their wordings and sequencing. The pilot involved all enumerators, supervisors - who were trained for 5 days on research methods, interviewing and the questionnaire - and researchers who later engaged in critical reflection and integration of the piloting results to make the questionnaire, and the items wording, sequencing, etc., as relevant and appropriate as possible.

Furthermore, the research team drew on their research and programing experiences on disability, community-based

rehabilitation and inclusion in Dabat district to ensure the culture-appropriateness and scientific validity of the tool.

Enumerators, after contacting household heads and informing them above the purpose of the study, asked them to provide information on household members with regard to impairment and/or disability by reading out a list of possible cases including hard of hearing or total loss, visual impairment or blind, speech impairment, loss of senses or limbs, paralysis, diagnoses insanity, etc. Due to stereotypes and stigma attached to disability, enumerators asked household heads to identify member with 'functional limitations' rather than directly asking them the question, "Is there anyone with disability in the household?" Enumerators applied items from WHODAS 2.0 or ICF-CY depending on the age of the individual disability information were provided for. The information gathered on disability through the community survey did not necessarily account for mild or minor types of impairments that household heads were not aware of and/or decided to be insignificant. As a result, the data collected and reported in this study were on complete/severe visual, auditory, motor or intellectual impairments sustained by household members.

The use of self-reporting rather than clinical diagnosis of household members to collect data on disability is identified as the limitation of this study. Whenever new cases of disability were identified during data collection, they were referred and/or linked to local Community-based Rehabilitation (CBR) fieldworkers.

\section{Data analysis}

Data were entered into the Household Registration System (v-2.1) and the survey data was entered into and analyzed using STATA (v.12) software. During data cleaning and organization, few items that were adapted from WHODAS 2.0 or ICF-CY but returned with questionable and unreliable responses were excluded to ensure the quality of the report. Descriptive statistics - means, percentages, standard deviation, etc. - were employed to 
describe the characteristics of the study population. Table and figures were used to present aggregated and disaggregated, as appropriate, data. Binary logistic regression was fitted to test and identify factors significantly associated with disability. The bivariate analysis was carried out, and variables with $p$-values of $<0.2$ were entered into the multivariable logistic regression model. The crude odds ratio (COR) and finally, a

Logistic regression models were constructed on predictors of disability among the study population. The adjusted odds ratios with the corresponding 95\% Confidence Interval (Cl) were used to show the strength of association between independent variables (age, sex, place of residence, religious affiliation, educational attainment, occupation marital status) and disability. A P value of $<0.05$ was considered statistically significant.

\section{Results}

Respondents' Socio-demographic characteristics: As (Table 1) and shows survey data was collected on 71,673 members of 17,000 households in Dabat district. Among this, 33,304 (50.7\%) were females, and 54,331 (75.77\%) lived in rural areas. The Table also reports that 22,055 (30.78\%) cannot read and write, while 22,093 (30.78\%) under 14years of age. Based on sex, $71.8 \%$ of female and $52.9 \%$ of male PwDs cannot read or write; and, females made up two-thirds of PwDs who cannot read or write.

Prevalence and types of disability: The overall prevalence of disability in Dabat district was 2.14\% [95\% Cl: 2.03, 2.24] i.e. 1537 out of 71,916 people were reported to have one or more types of impairments listed on the questionnaire. Higher prevalence was noted among females (2.29\%) than males (1.97\%). As Table 2 and Figure 1 reveal, the prevalence of disability increased with increase in age, and reached the highest level among persons of 65 and above years old (10.18\%). Conversely, without alluding causal attribution, the prevalence of disability declined with increase in educational status. For instance, the highest proportion of disability - 971 (63.2\%\%) was recorded among those who cannot read and write, and the difference is stark when we compare it to those with Grade 11/12 (0.72\%) and Grade 12-plus (0.98\%) education (Table 2 and 3) (figure 1 ).

More than $8 \%$ of households had a member with disability (1411 in 17,000 households). Table 1 also reports that the prevalence of disability was high among those with 'separated' (63 (10.21\%)) and widowed (176 (9.33\%)) marital statuses as well as the unemployed (5.42\%). There was marginal variation between urban (2.08\%) and rural (2.15\%) Kebeles of Dabat district in terms of the number of persons affected by disability (Table 2).

Eight percent of the PwDs had more than one type of disability. In terms of single-disabilities, $51 \%$ had visual impairment, while $22.3 \%$ had mobility impairment and $22.3 \%$ were hard of hearing. there was a marked increase in hearing and visual impairments among ageing respondents (Table 3 \& Figure 2, 3).

On the other hand, only 253 (16.5\%) PwDs attended any form of formal education. In fact, as educational level increases, the proportion of PwDs who attended higher grade-levels fell significantly with less than $1 \%$ completing secondary education (Table 4).

With regard to occupation, small proportions of PwDs were government employees in urban (2.03\%) and rural (0.35\%) areas. More men (urban, $20.2 \%$; rural, $52.8 \%$ ) than women (urban, $14.8 \%$; rural, $47.1 \%$ ) worked on the farm, and farming was the main occupation for residents in urban (17\%) and rural (49.8\%) areas (Table 5). Conversely, more women (urban, $24.1 \%$ vs. $14.6 \%$; rural, $17.8 \%$ vs. $7.9 \%$ ) were household servants, while more men (urban, $12.3 \%$ vs. $8.1 \%$; rural, $11.1 \%$ vs. $1.3 \%$ ) were engaged in private works compared to their women counterparts (Table 5). 
The survey identified the most frequent causes of disability as illness (36.93\%), followed by accidents (17.81\%), unknown (11.57\%), congenital (10.86\%) and ageing (5.2\%). In other words, more than $83 \%$ of the reported immediate causes of impairments could have been prevented from causing functional limitations if they were identified and treated early (Table 6 and Figure 4). This argument is congruent to studies in other African and Latin American settings where families and persons with impairments are more likely to avoid early treatment (44), seek the services of traditional healers than modern medicine (40) or suffer from the inadequacy of primary health care services for screening and treatment (30).

Factors associated with disability: Multivariate logistic regression model was constructed to predict the occurrence of disability in the study population from data on respondents' age, educational attainment and marital status. The model found age [AOR=1.0; 95\% Cl: 1.03, 1.04], educational attainment [AOR=1.15;95\% Cl: 1.57, 2.13], and marital status i.e. being single [AOR: 1.39; 95\% Cl: 185,2.47] and separated [AOR: 2.78; 95\% Cl: 4.14,6.19] as significant predictors of disability in the study population (Table 7).

\section{Discussion}

This study found that though the general prevalence of disability was $2.14 \%$, it significantly affects older persons in the community. The proportion of households with members with disability i.e., 8.3\% was high when compared to previous studies on the study area. As questionable they were in reliability, representativeness or timeliness, CSA and Chala reported $1.82 \%$ and $1.09 \%$, respectively, disability prevalence for Dabat district, which were significantly lower than the $2.14 \%$ reported in this study. However, $2.14 \%$ is still significantly lower than an estimated $17.6 \%$ national disability prevalence rate in Ethiopia that WHO and WB (2011) reported.

There are several possible explanations why different sources provide different reports on the prevalence of disability. For one, WHO conceptualize disability broadly and include various factors and types, such chronic illnesses as diabetics as well as moderate and minor impairments, within the rubric of 'disability.' However, limited resources for rehabilitation services and supporting PwDs in developing countries may have dictated a narrower operationalization of disability. In other words, pragmatic conceptualization of disability would set realistic expectations and recommendations for policy formulation and social work practice. For another, this study relied on responses household heads provided to estimate the prevalence of disability in the district. By its design, the quality of data could be affected by respondents' lack of knowledge on the nature and degree of one's and household members' disability, and negative attitude towards disability and PwDs, among other. Hence, lack of understanding on disability, stigma attached to disability in the district and respondents' inability to identify all types and degrees of disability may have lowered reports on disability in the study area.

In terms of type of disability, this study reported similar results as the same team's previous study in Dabat district. Both studies found that visual impairment affects the highest proportion of PwDs; but while the current study found that mobility and hearing impairments are second and third in the number of persons they affect, their relative proportion was reversed three years earlier.

A small fraction of PwDs attended formal education; and more importantly, with advance in educational level, their progression to higher grades decreases significantly. This result was consistent with the Handicap International report that indicated a small fraction (3\%) of the estimated 2.4 to 4.8 million school-age CwDs went to school. CwDs' low school attendance and participation are due to underlaying reasons that include stigma against CwDs, school inaccessibly, rigid teaching practice, poorly trained teachers to accommodate children with special needs 
and lack of adaptive hearing resources. Another study in South Africa documented how PwDs and their families live with stigma and social exclusion that affect their personal development and community participation. Other studies also report CwDs are less likely to attend schooling and access health care, and they are more vulnerable to poverty which may result in substantial decline in their quality of life.

This study reported that the majority of disabilities were due to modifiable illnesses, injuries, etc.; and the causes and impacts of disability are multifaceted. Concurrent to these findings, studies have documented that the majority of disabilities in Africa result from illness, injury, and accidents - causes that are preventable $(5,45,46)$. In Ethiopia, diseases like measles, poliomyelitis, etc. as well as accidents and injuries cause illnesses to many people that - if identified and treated early or on time - may not necessarily amount to serious functional and activity limitations. This does not necessary amount to disability entirely avoided for individuals concerned - but that if trachoma, measles, illnesses, etc. could be treated early and prevented from causing serious damage to the body organism thereby reducing the severity impairment and/or enabling functionality. This scenario is not unique to Ethiopia as, for instance, a study on nine Latin American countries categorized $80 \%$ of visual impairments as avoidable with early detect and treatment [30]. Most disabilities and their causes can be linked to poverty, and restricted access to basic services. As this study reported, most PwDs were poor - both in urban and rural areas and a significant majority of them were involved in small-scale farming with strained livelihoods. Besides, inadequate health care services, poor health literacy and health seeking behavior could were also contribute to the disability problem on the continent, which is the same in the Dabat district.

Disability causes serious bad health outcomes, and the provision of long-term care for PwDs in resource limited settings is a major public health problem. Disability is especially a concern for developing countries where prevention approach and health service services are inadequate or very scarce $(40,47)$. Moreover, stigma and stereotypes limit educational and employment opportunities for PwDs thereby creating dependency and exclusion for PwDs and this study underlines these facts.

When it comes to women with disabilities, they carry the double burden of stigma and discrimination and economic problem due to their gender-roles and disability. Disability and poverty exacerbate their socioeconomic wellbeing and their general quality of life.

\section{Strengths and Limitations}

The study aimed at exploring the prevalence, types and causes of severe disability in low resource setting i.e., Dabat district, Northwestern Ethiopia. Literature review revealed that there is dearth of scientific, empirical information to understand the trend and changes on the prevalence and magnitude of disability and its effects in Ethiopia. It has also established the evident fact that there is low community and governmental attention on disability and the empowerment of PwDs in developing countries such as Ethiopia. Therefore, by identifying contributing factors to disability and its prevalence and impacts on peoples' lives in northwest Ethiopia, this study will promote disability awareness and inclusive society as well as inform the agenda for disability research, policy and practice in the district and beyond. To this end, large sample was drawn to collect representative empirical data about the population.

The two main limitations of this study emanate from drawing on the reports of household heads to identify PwDs at the household level, and the focus on severe/extreme functional limitations due to impairments rather than the 
whole range of impairments/disabilities. The researchers attempted to address the first limitation to a certain extent by listing possible types of impairments/disabilities to help household heads frame and/or prompt their responses. Due to the large sample size i.e., 17,000 households the researchers could not employ disability screening as a method of data collection. Consequently, the reported disability prevalence in the district was significantly lower than the WHO estimation for low- and middle-income countries. But we have to take into account the fact that household heads reported visible and severe impairment.

\section{Conclusion}

This study found the proportion of reported disability per household to be high. Vision and mobility disability were the most frequently observed types of disability, and most immediate causes of disability were modifiable. This conclusion, however, does not apply to underlying structural factors to disability such as poverty, aging, inaccessibility of health services, etc. that require programmatic interventions at national, regional and local levels. On the other hand, this study indicated that the prevalence of disability increased among the ageing-groups. As educational level increase, the proportion of PwDs attending school decreases, and most PwDs do not complete secondary education. Similarly, a small proportion of PwDs were government employees, and the majority were engaged in farming.

Early intervention and appropriate medication will prevent the burden of disability. To this end, appropriate attention should be given to improve quality of healthcare facilities and services to reduce the burden of disability on families, communities and the health care system. Moreover, community awareness creation and enhancing inclusive education will improve education opportunity for PwDs. With improve in educational level and skills, PwDs will be able to find and/or create jobs thereby promoting their independence and better quality of life. Further qualitative research is recommended to examine contextual factors that influence the social participation and quality of life of PwDs in the context of Dabat district.

\section{Abbreviations}

ANRS: Amhara National Regional State

CBR: Community-based Rehabilitation

CSA: Central Statistical Agency

CwDs: Children with Disabilities

DHSS: Demographic Health Surveillance System

ICF: International Classification of Functioning, Health and Disability

ICF-CY: Health and Disability, Children \& Youth version

NGZ: North Gondar Zone

PwDs: Persons with Disabilities

WB: World Bank 
WHO: The World Health Organization

WHODAS 2.0: World Health Organization Disability Assessment Schedule

\section{Declarations}

\section{Ethics approval and consent to participate}

The University of Gondar's Institutional Review Board (UoG-IRB) cleared the research for meeting required and appropriate ethical standards. Two support letters - from the Vice President's Office for Research and Community Services and the College of Medicine and Health Sciences - were submitted to Dabat District Administrator. Letter of information describing the purpose and objectives of the study, and written informed consent was obtained from the study participant (household head), and consent forms were given or read to study participants prior to the commencement of the interview. Participants were granted the right to terminate their participation in the study at any point if and when they chose to.

Once in the field, researchers and DHSS staff put their maximum efforts in assuring all ethical and scientific standards are maintained. Participants' privacy and confidentiality were respected during and after interviews. Once data was collected, each questionnaire was coded, and personal identifiers were removed to maintain anonymity and confidentiality of participants. All data was entered and saved on a computer with a strong password which was only accessible by the research team. Participants who reported disability or were found ill during data collection were either linked to UoG-CBR fieldworkers or health centers for better care.

Consent for publication: "Not applicable"

Availability of data and material: Since the data presented in this report are the part of the large DHSS survey data, we have to abide by the data sharing policy of University of Gondar; nonetheless, we have included all important information regarding data presented on the tables and figures (No additional data are available).

Competing interests: The authors declare no financial and non-financial competing interests

Funding: The funder body (University of Gondar, Ethiopia), has no role in the design of the study and collection, analysis, and interpretation of data and in writing the manuscript.

\section{Authors' contributions}

SMA, MB, MB, SF, AN, MA, Z, WW, AF, designed the study;

SMA, performed the analysis and interpretation of data; and,

SMA, MB, MB, SF, AN, MA, Z, WW, AF, drafted and finalized the write-up of the paper.

All authors prepared the draft manuscript, read and approved the final manuscript.

\section{Acknowledgement}


We would like to acknowledge the University of Gondar for the financial support. We extend our thanks to the Dabat District Health Office for their permission to conduct the study. We want to express our gratitude to all staff of the Dabat DHS and the study participants.

\section{Authors' Information}

We confirm that the manuscript has been read and approved by all named authors,

\section{References}

1. World Health Organization and the World Bank. 2011. World Report on Disability. Geneva: The World Health Organization.

2. Cohen ME, Marino RJ: The tools of disability outcomes research functional status measures. Archives of physical medicine and rehabilitation 2000, 81(12 Suppl 2):S21-29.

3. . In: Survey Measurement of Work Disability: Summary of a Workshop. edn. Edited by Mathiowetz N, Wunderlich GS. Washington (DC); 2000.

4. 2007 POPULATION and HOUSING CENSUS OF ETHIOPIA. In. Addis Ababa: Central Statistical Authority; 2012.

5. Sida: September 2014. Disability rights in Ethiopia.

(https://www.sida.se/globalassets/sida/eng/partners/human-rights-based-approach/disability/rights-ofpersons-with-disabilities-ethiopia.pdf. Accesed on June 27, 2020).

6. Girmachew Gashaw: Proper Disability Census for Inclusive Development. Ethiopia Semonegna, Accessed on June 27, . In.; December 32018.

7. Hong T, Mitchell P, Burlutsky G, Liew G, Wang JJ: Visual Impairment, Hearing Loss and Cognitive Function in an Older Population: Longitudinal Findings from the Blue Mountains Eye Study. PloS one 2016, 11(1):e0147646.

8. Fitaw Y, Boersma JM: Prevalence and impact of disability in north-western Ethiopia. Disability and rehabilitation 2006, 28(15):949-953.

9. Tamrat G, Kebede Y, Alemu S, Moore J: The prevalence and characteristics of physical and sensory disabilities in Northern Ethiopia. Disability and rehabilitation 2001, 23(17):799-804.

10. Krahn GL: WHO World Report on Disability: a review. Disability and health journal 2011, 4(3):141-142.

11. World report on disability. Lancet 2011, 377(9782):1977.

12. Organization IL: Inclusion of People with Disabilities in Ethiopia. In.; 2013.

13. Alemu T, Fantahun M: Sexual and reproductive health status and related problems of young people with disabilities in selected associations of people with disability, Addis Ababa, Ethiopia. Ethiopian medical journal 2011, 49(2):97-108.

14. RIESER R: Issues of gender, 'race', sexuality, disability and social class: Disability equality: Confronting the oppression of the past. Taylor \& Francis press 2006.

15. Getachew AT: Attitudes of Ethiopian college students toward people with visible disabilities. University of lowa a Research Online; 2011. 
16. Sumilo D, Kurinczuk JJ, Redshaw ME, Gray R: Prevalence and impact of disability in women who had recently given birth in the UK. BMC pregnancy and childbirth 2012, 12:31.

17. Kuper H, Monteath-van Dok A, Wing K, Danquah L, Evans J, Zuurmond M, Gallinetti J: The impact of disability on the lives of children; cross-sectional data including 8,900 children with disabilities and 898,834 children without disabilities across 30 countries. PloS one 2014, 9(9):e107300.

18. Dassah E, Aldersey H, McColl MA, Davison C: Factors affecting access to primary health care services for persons with disabilities in rural areas: a "best-fit" framework synthesis. Global health research and policy 2018, 3:36.

19. Tarvonen-Schroder S, Hurme S, Laimi K: The World Health Organization Disability Assessment Schedule (WHODAS 2.0) and the WHO Minimal Generic Set of Domains of Functioning and Health versus Conventional Instruments in subacute stroke. Journal of rehabilitation medicine 2019, 51(9):675-682.

20. Ethiopia Demographic and Health Survey: Calverton, Maryland, USA: CSA and ICF International. In. Cover photograph: (C) 2003 Chandrakant Ruparelia, Courtesy of Photoshare 2011.

21. Chala MB, Mekonnen S, Andargie G, Kebede Y, Yitayal M, Alemu K, Awoke T, Wubeshet M, Azmeraw T, Birku M et al: Prevalence of disability and associated factors in Dabat Health and Demographic Surveillance System site, northwest Ethiopia. BMC public health 2017, 17(1):762.

22. Ribohn U: Human rights for persons with disabilities; an evaluation of the work plan. In. Edited by 30 : Commissioned by Sida, Department for International Organisations and Policy Support; 2013.

23. Lorenzo T, van Pletzen E, Booyens M: Determining the competences of community based workers for disability-inclusive development in rural areas of South Africa, Botswana and Malawi. Rural and remote health 2015, 15(2):2919.

24. Khoo TB, Kassim AB, Omar MA, Hasnan N, Amin RM, Omar Z, Yusoff AF: Prevalence and impact of physical disability on Malaysian school-aged children: a population-based survey. Disability and rehabilitation 2009, 31(21):1753-1761.

25. Lerner WM, Weil PA, Kirschner KL: The prevalence and impact of disability among healthcare executives. Healthcare executive 2006, 21(6):24-26, 28-29.

26. G. Tamrat YK, S. Alemu and J. Moore.: The Prevalence and Characteristics of Physical and Sensory Disabilities in Northern Ethiopia. Disability and rehabilitation 2001, 23(17, 20):799-804.

27. (CARDOS) CfARaDOS: Report on the general conditions of people with disabilities in Ethiopia. Addis Ababa. 2007.

28. (ACPF) ACPF: Educating Children with Disabilities in Africa: Towards a policy inclusion. In. Addis Ababa, Ethiopia 2011.

29. Rieser R: Disability equality: confronting the oppression of the past. In: Education Equality and Human Rights: issues of gender, 'race', sexuality, disability and social class. edn. Edited by Cole M: Routledge Taylor \& Francis press; 2006.

30. Amador, Mercedes and Javier Torres. 2019. Visual Disability and Causes of Preventable Blindness [in book Primary Care: Working Title], IntechOpen (DOI: 10.5772/intechopen.88793. Accessed on September 27, 2020, https://www.intechopen.com/online-first/visual-disability-and-causes-of-preventable-blindness)

31. Finkelstein (1980, p 47) cited in Burchardt, Tania (2004) "Capabilities and disability: the capabilities framework and the social model of disability." Disability \& Society, 19:7, 735-751 
32. Hughes, Bill and Paterson, Kevin (1997) "The Social Model of Disability and the Disappearing Body: Towards a sociology of impairment.' Disability \& Society, 12: 3, $325-340$

33. Van Brakel, Wim and Alana Officer. 2007. "Approaches and tools for measuring disability in low and middleincome countries." Lepr Rev 79, 50-64 34. Gezahegn B., \& Yinebeb T. (2010). "Attitude of teachers towards inclusive education in Ethiopia." Ethiopian Journal of Education and Science, 6(1), 89-96.

34. Singal, N., \& Muthukrishna, N. (2014). "Education, childhood and disability in countries of the South - Repositioning the debates." Childhood, 21(3), 293-307.

35. Naidoo, Kovin, Avesh Raghunandan, Khathutshelo Mashige, Pirindhavellie Govender, Brien Holden, Gopal Pokharel, Leon Ellwein. 2003. "Refractive Error and Visual Impairment in African Children in South Africa” Investigative Ophthalmology \& Visual Science. 44 (9): 3764-3770.

36. Kahloun, R, B Jelliti, S Zaouali, S Attia, S Ben Yahia, S Resnikoff\& M Khairallah. 2014. "Prevalence and causes of visual impairment in diabetic patients in Tunisia, North Africa" Eye 28: 986-991

37. Amoakoh, Hannah and Aikins, Moses. 2012. Household cost of out-patient treatment of Buruli ulcer in Ghana: a case study of Obom in Ga South Municipality. BMC Health Services Research 13, 1-8

38. Mulatu M. S. (1999) "Perceptions of mental and physical illnesses in north-western Ethiopia: causes, treatments and attitudes." Journal of Health Psychology 4, 531-49.

39. Aldersey, H.M., 2012. Family perceptions of intellectual disability: understanding and support in Dar es Salaam. African Journal of Disability 1 (1): 1-12

40. Bethlehem Tekolaa, Mersha Kinfe, Fikirte Girma, Charlotte Hanlonb, Rosa Hoekstraa. 2020. “Perceptions and experiences of stigma among parents of children with developmental disorders in Ethiopia: A qualitative study" Social Science and Medicine 256: 1-9.

41. Oti-Boadi, M., 2017. Exploring the lived experiences of mothers of children with intellectual disability in Ghana. SAGE Open 7 (4), 1-12.

42. Gona, J.K., Newton, C.R., Rimba, K., Mapenzi, R., Kihara, M., Van de Vijver, F.J., Abubakar, A., 2015. Parents' and professionals' perceptions on causes and treatment options for autism spectrum disorders (ASD) in a multicultural context on the Kenyan coast. Plos One 10 (8).

43. Berhanu Boru Bifftu, WubetWorku Takele, Yonas Deressa Guracho, and Fekadu Ambaw Yehualashet. 2018. "Depression and Its Help Seeking Behaviors: A Systematic Review and Meta-Analysis of Community Survey in Ethiopia." Depression Research and Treatment. Volume 2008, 1-11.

44. Ikenna D. Ebuenyi, Barbara J. Regeer, David M. Ndetei, Joske F. G. Bunders-Aelen and Mònica Guxens. 2019. "Experienced and Anticipated Discrimination and Social Functioning in Persons with Mental Disabilities in Kenya: Implications for Employment." Frontier in Psychiatry, 10 (181): 1-9.

45. Gona, Joseph, Charles Newton, Kenneth Rimba, Rachel Mapenzi, Michael Kihara, Fons, JR Van de Vijver, and Amina Abubakar. 2015. "Parents' and Professionals' Perceptions on Causes and Treatment Options for Autism Spectrum Disorders (ASD) in a Multicultural Context on the Kenyan Coast." PLoS ONE 10(8): 1-13.

46. Mbwilo, G.S.K., Smide, B. \& Aarts, C., 2010, 'Family perceptions in caring for children and adolescents with mental disabilities: A qualitative study from Tanzania',Tanzania Journal of Health Research 12(2), 1-12

\section{Tables}

Table 1: Socio-demographic characteristics of the study population by sex $(n=71,653)$ at Dabat district 


\begin{tabular}{|l|r|r|r|}
\hline Variable & Female, $\mathbf{n}(\%)$ & Male, $\mathbf{n}(\%)$ & \multicolumn{1}{|l|}{ Total, $\mathbf{n}(\%)$} \\
\hline Age (in year) & & & \\
\hline 0 to 14 Years & $11,023(49.9)$ & $11,070(50.1)$ & $22,093(30.8)$ \\
\hline 15 to 24 Years & $8,557(49.2)$ & $8,837(50.8)$ & $17,394(24.3)$ \\
\hline 25 to 34 Years & $5,745(52.2)$ & $5,265(47.8)$ & $11,010(15.4)$ \\
\hline 35 to 44 years & $4,177(53.9)$ & $3,574(46.1)$ & $7,751(10.8)$ \\
\hline 45 to 54 years & $2,776(50.6)$ & $2,715(49.4)$ & $5,491(7.66)$ \\
\hline 55 to 64 years & $2,142(54.3)$ & $1,806(45.7)$ & $3,948(5.5)$ \\
\hline 65 and above years & $1,884(47.5)$ & $2,082(52.5)$ & $3,966(5.54)$ \\
\hline Educational attainment & & & \\
\hline Under age (17years) & $9584(49.3)$ & $9856(50.7)$ & $19,440(27.13)$ \\
\hline Unable to read and write & $12814(58.1)$ & $9241((41.9)$ & $22,055(30.78)$ \\
\hline Able to read and write & $1034(23.47)$ & $3371(76.53)$ & $4,405(6.15)$ \\
\hline Grade 1 to 3 & $3697(45.4)$ & $4452(54.6)$ & $8,249(11.37)$ \\
\hline Grade 4 to 6 & $2210(49.2)$ & $2281(50.8)$ & $4,491(6.27)$ \\
\hline Grade 7 to 8 & $1220(52.6)$ & $1099(47.4)$ & $2,319(3.24)$ \\
\hline Grade 9 to 10 & $1765(57)$ & $1332(43)$ & $3097(4.32)$ \\
\hline Grade 11 to 12 & $687(59.2)$ & $474(40.8)$ & $1161(1.62)$ \\
\hline Above 12 & $484(47.45)$ & $536(52.55)$ & $1020(1.42)$ \\
\hline Unknown & $2809(50.9)$ & $2706(49.1)$ & $5515(7.70)$ \\
\hline Marital Status & & & \\
\hline Under age $\square 10$ years & $12,943(49.04)$ & $13,451(50.96)$ & $26,394(36.8)$ \\
\hline Married & $11,510(52.4)$ & $10,456(47.6)$ & $21,966(30.66)$ \\
\hline Single & $5,688(39.4)$ & $8,757(60.6)$ & $14,445(20.2)$ \\
\hline Divorced & $1,861(80.8)$ & $442(19.2)$ & $2.303(3.2)$ \\
\hline Widowed & $1,664(89.99)$ & $185(10.01)$ & $1,849(2.58)$ \\
\hline Separated & $485(84.3)$ & $90(15.7)$ & $575(0.80)$ \\
\hline Unknown & $2153(52.2)$ & $1,968(47.8)$ & $4121(5.75)$ \\
\hline Place of Residence & & & \\
\hline Urban & $9,778(56.45)$ & $7,543(43.55)$ & $17,321(24.7)$ \\
\hline Rural & $26,526(48.8)$ & $27,805(51.2)$ & $54,331(75.3$ \\
\hline Religion & & & \\
\hline Orthodox Christianity & $35,095(50.6)$ & $34,203(49.4)$ & $69,298(96.71$ \\
\hline Islam & $1,202(51.4)$ & $1,139(48.6)$ & $2,341(3.27)$ \\
\hline Catholic/ Protestant & $7((50.0)$ & $7(50.0)$ & $14(0.02)$ \\
\hline
\end{tabular}

Table 2: Distribution disability by Socio-demographic characteristics of the study population $(n=71,653)$ at Dabat DHSS 


\begin{tabular}{|c|c|}
\hline Variable & Disability Yes \# (\%) \\
\hline \multicolumn{2}{|l|}{ Age in years } \\
\hline 0 to 14 Years & $194(0.88)$ \\
\hline 15 to 24 Years & $194(1.11)$ \\
\hline 25 to 34 Years & $175(1.58)$ \\
\hline 35 to 44 years & $184(2.36)$ \\
\hline 45 to 54 years & $179(3.24)$ \\
\hline 55 to 64 years & $201(5.06)$ \\
\hline 65 and above years & $410(10.18)$ \\
\hline Total & $1537(2.14)$ \\
\hline \multicolumn{2}{|l|}{ Sex } \\
\hline Female & $837(2.3)$ \\
\hline Male & $700(1.97)$ \\
\hline Total & $1537(2.14)$ \\
\hline \multicolumn{2}{|l|}{ Residency } \\
\hline Urban & $363(2.08)$ \\
\hline Rural & $1174(2.15)$ \\
\hline Total & $1537(2.14)$ \\
\hline \multicolumn{2}{|l|}{ Religion } \\
\hline Orthodox Christianity & $1312(1.87)$ \\
\hline Islam & $25(1.01)$ \\
\hline Total & $1537(2.14)$ \\
\hline \multicolumn{2}{|l|}{ Educational Status } \\
\hline Under age ( $\square 7$ years) & $153(0.79)$ \\
\hline Unable to read and write & $971(4.36)$ \\
\hline Able to read and writ & $130(2.95)$ \\
\hline Grade 1 to 3 & $88(1.08)$ \\
\hline Grade 4 to 6 & $57(1.27)$ \\
\hline Grade 7 to 8 & $36(1.55)$ \\
\hline Grade 9 to 10 & $41(1.32)$ \\
\hline Grade 11 to 12 & $11(0.95)$ \\
\hline Above grade 12 & $15(1.47)$ \\
\hline Unknown & $35(0.63)$ \\
\hline Total & $1537(2.14)$ \\
\hline \multicolumn{2}{|l|}{ Marital Status } \\
\hline Underage ( $\$ 15$ years old) & $209(0.79)$ \\
\hline Married & $664(3.01)$ \\
\hline Single & $287(1.98)$ \\
\hline Divorced & $104(4.49)$ \\
\hline Widowed & $176(9.33)$ \\
\hline Separate & $63(10.21)$ \\
\hline Cohabited & $0(0.00)$ \\
\hline Unknown & $25(0.61)$ \\
\hline Total & $1537(2.14)$ \\
\hline Variable & Disability Yes \# (\%) \\
\hline \multicolumn{2}{|l|}{ Occupation } \\
\hline Underage ( 10 years) & $286(0.98)$ \\
\hline Farmer & $408(3.77)$ \\
\hline Merchant & $71(1.45)$ \\
\hline Private employee & $35(2.35)$ \\
\hline Government employee & $12(2.47)$ \\
\hline Daily laborer & $31(3.78)$ \\
\hline Housewife & $68(3.69)$ \\
\hline
\end{tabular}




\begin{tabular}{ll}
\hline Shepherd & $228(3.34)$ \\
\hline Student & $151(2.3)$ \\
\hline Home-made servant & $162(2.75)$ \\
\hline Unemployed & $28(5.42)$ \\
\hline Others & $37(1.51)$ \\
\hline Total & $1537(2.14)$ \\
\hline
\end{tabular}

Table 3: Distribution and types of disability by age $(n=1537)$ at Dabat district (in percent)

\begin{tabular}{lllllllll}
\hline Age in year & Hearing & Vision & Mental & Speech & Learning & Motor & Other & Total \\
\hline 0 to 14 & 0.09 & 0.22 & 0.15 & 0.10 & 0.06 & 0.28 & 0.01 & 0.92 \\
\hline 15 to 4 & 0.23 & 0.28 & 0.19 & 0.09 & 0.09 & 0.305 & 0.02 & 1.22 \\
\hline 25 to 34 & 0.30 & 0.40 & 0.30 & 0.09 & 0.08 & 0.35 & 0 & 1.53 \\
\hline 35 to 44 & 0.49 & 0.73 & 0.27 & 0.13 & 0.05 & 0.55 & 0.05 & 2.28 \\
\hline 45 to 54 & 0.58 & 1.29 & 0.36 & 0.183 & 0.10 & 0.64 & 0.05 & 3.22 \\
\hline 55 to 64 & 0.88 & 3.01 & 0.25 & 0.13 & 0.05 & 0.76 & 0.05 & 5.14 \\
\hline 64 and above & 2.27 & 6.88 & 0.28 & 0.13 & 0.00 & 1.21 & 0.05 & 10.82 \\
\hline Total & & & & & & & &
\end{tabular}

Table 4: Educational attainment by sex among PwDs in Dabat district

\begin{tabular}{lccc}
\hline Educational attainment & Female, $\mathbf{n}(\%)$ & Male, $\mathbf{n ~ ( \% )}$ & Total, $\mathbf{n}(\%)$ \\
\hline Under age (口7years) & $83(9.92)$ & $100(14.3)$ & $183(11.9)$ \\
Unable to read and write & $601(71.8)$ & $370(52.9)$ & $971(63.2)$ \\
\hline Able to read and writ & $18(2.15)$ & $112(16)$ & $130(8.46)$ \\
\hline Grades 1 to 3 & $56(6.69)$ & $33(4.71)$ & $89(5.79)$ \\
\hline Grades 4 to 6 & $25(2.99)$ & $34(4.86)$ & $59(3.84)$ \\
\hline Grades 7 to 8 & $20(2.39)$ & $17(2.43)$ & $37(2.41)$ \\
\hline Grades 9 to 10 & $21(2.51)$ & $21(3)$ & $42(2.73)$ \\
\hline Grades 11 to 12 & $5(0.6)$ & $6(0.86)$ & $11(0.72)$ \\
\hline Grades $12+$ & $8(0.96)$ & $7(1)$ & $15(0.98)$ \\
\hline Total & $\mathbf{8 3 7 ( 5 4 )}$ & $\mathbf{7 0 0 ( 4 6 )}$ & $\mathbf{1 5 3 7 ( 1 0 0 )}$ \\
\hline
\end{tabular}

Table 5: Occupation by sex and residential area among PwDs in Dabat district 


\begin{tabular}{lllllll}
\hline $\begin{array}{l}\text { Variable } \\
\text { Occupation }\end{array}$ & Female & \multicolumn{1}{c}{ Urban } & Total & Female & $\begin{array}{c}\text { Rural } \\
\text { Male }\end{array}$ & Total \\
\hline Under age & $55(23.3)$ & $41(25.9)$ & $96(24.4)$ & $127(21.1)$ & $75(13.8)$ & $202(17.7)$ \\
\hline Farmer & $35(14.8)$ & $32(20.2)$ & $67(17.0)$ & $283(47.1)$ & $286(52.8)$ & $569(49.8)$ \\
\hline Private employment & $19(8.05)$ & $19(12.03)$ & $38(9.64)$ & $8(1.33)$ & $60(11.1)$ & $68(5.95)$ \\
\hline Government employed & $4(1.69)$ & $4(2.53)$ & $8(2.03)$ & $2(0.33)$ & $2(0.37)$ & $4(0.35)$ \\
\hline Daily laborer & $11(4.66)$ & $12(7.59)$ & $23(5.84)$ & $2(0.33)$ & $6(1.11)$ & $8(0.70)$ \\
\hline Home Made & $57(24.1)$ & $23(14.6)$ & $80(20.3)$ & $107(17.8)$ & $43(7.93)$ & $150(13.1)$ \\
\hline Student & $44(18.6)$ & $22(13.9)$ & $66(16.7)$ & $50(8.32)$ & $47(8.67)$ & $97(8.49)$ \\
\hline Unemployed & $11(4.66)$ & $5(3.16)$ & $16(4.06)$ & $22(3.66)$ & $23(4.24)$ & $45(3.94)$ \\
\hline
\end{tabular}

(Source: Survey 2018)

Table 6: Distribution of perceived causes and types of disability among the study population in Dabat district

\begin{tabular}{|c|c|c|c|c|c|c|c|c|c|c|c|c|}
\hline \multirow[t]{2}{*}{ Variable } & \multicolumn{2}{|c|}{ Hearing } & \multicolumn{2}{|c|}{ Vision } & \multicolumn{2}{|c|}{$\begin{array}{l}\text { Physical } \\
\text { disability }\end{array}$} & \multicolumn{2}{|c|}{ Mental } & \multicolumn{2}{|c|}{ Speech } & \multicolumn{2}{|c|}{ Learning } \\
\hline & Yes & Total & Yes & Total & Yes & Total & Yes & Total & Yes & Total & Yes & Total \\
\hline Congenital & $\begin{array}{c}54 \\
(15.7)\end{array}$ & $\begin{array}{c}167 \\
(10.9)\end{array}$ & $\begin{array}{c}29 \\
(3.7)\end{array}$ & $\begin{array}{c}167 \\
(10.8)\end{array}$ & $\begin{array}{c}48 \\
(12.9)\end{array}$ & $\begin{array}{c}167 \\
(10.9)\end{array}$ & $\begin{array}{c}35 \\
(17.8)\end{array}$ & $\begin{array}{c}167 \\
(10.9)\end{array}$ & $\begin{array}{c}38 \\
(36.5)\end{array}$ & $\begin{array}{c}167 \\
(10.9)\end{array}$ & $\begin{array}{c}29 \\
(42.6)\end{array}$ & $\begin{array}{c}167 \\
(10.9)\end{array}$ \\
\hline Grievance & $\begin{array}{c}7 \\
(2.04)\end{array}$ & $\begin{array}{c}67 \\
(4.36)\end{array}$ & $\begin{array}{c}49 \\
(6.25)\end{array}$ & $\begin{array}{c}67 \\
(4.36)\end{array}$ & $\begin{array}{c}14 \\
(3.73)\end{array}$ & $\begin{array}{c}67 \\
(4.36)\end{array}$ & $\begin{array}{c}9 \\
(4.57)\end{array}$ & $\begin{array}{c}67 \\
(4.36)\end{array}$ & $\begin{array}{c}3 \\
(2.88)\end{array}$ & $\begin{array}{c}67 \\
(4.36)\end{array}$ & $1(1.47)$ & $\begin{array}{c}67 \\
(4.36)\end{array}$ \\
\hline Injury & $\begin{array}{c}38 \\
(11.08)\end{array}$ & $\begin{array}{c}274 \\
(17.8)\end{array}$ & $\begin{array}{c}126 \\
(16.1)\end{array}$ & $\begin{array}{c}274 \\
(17.8)\end{array}$ & $\begin{array}{c}113 \\
(30.3)\end{array}$ & $\begin{array}{c}274 \\
(17.8)\end{array}$ & $\begin{array}{c}18 \\
(9.14)\end{array}$ & $\begin{array}{c}274 \\
(17.8)\end{array}$ & $\begin{array}{c}8 \\
(7.69)\end{array}$ & $\begin{array}{c}266 \\
(18.6)\end{array}$ & $5(7.35)$ & $\begin{array}{c}274 \\
(17.8)\end{array}$ \\
\hline Meseal & $\begin{array}{c}8 \\
(2.33)\end{array}$ & $\begin{array}{c}20 \\
(1.3)\end{array}$ & $\begin{array}{c}12 \\
(1.53)\end{array}$ & $\begin{array}{c}20 \\
(1.3)\end{array}$ & $\begin{array}{c}3 \\
(0.8)\end{array}$ & $\begin{array}{c}20 \\
(1.3)\end{array}$ & $\begin{array}{c}0 \\
(0.00)\end{array}$ & $\begin{array}{c}20 \\
(1.3)\end{array}$ & $\begin{array}{c}0 \\
(0.00)\end{array}$ & $\begin{array}{l}20 \\
(1.3)\end{array}$ & $0(0.00)$ & $\begin{array}{c}20 \\
(1.3)\end{array}$ \\
\hline Old age & $\begin{array}{c}30 \\
(8.75)\end{array}$ & $\begin{array}{c}80 \\
(5.2)\end{array}$ & $\begin{array}{c}64 \\
(8.16)\end{array}$ & $\begin{array}{c}80 \\
(5.2)\end{array}$ & $\begin{array}{c}9 \\
(2.41)\end{array}$ & $\begin{array}{c}80 \\
(5.2)\end{array}$ & $\begin{array}{c}3 \\
(1.52)\end{array}$ & $\begin{array}{c}80 \\
(5.2)\end{array}$ & $\begin{array}{c}2 \\
(1.92)\end{array}$ & $\begin{array}{c}80 \\
(5.2)\end{array}$ & $1(1.47)$ & $\begin{array}{c}80 \\
(5.2)\end{array}$ \\
\hline Spontaneously & $\begin{array}{c}16 \\
(4.66)\end{array}$ & $\begin{array}{c}51 \\
(3.32)\end{array}$ & $\begin{array}{c}23 \\
(2.93)\end{array}$ & $\begin{array}{c}51 \\
(3.32)\end{array}$ & $\begin{array}{c}2 \\
(0.54)\end{array}$ & $\begin{array}{c}51 \\
(3.32)\end{array}$ & $\begin{array}{c}10 \\
(5.08)\end{array}$ & $\begin{array}{c}51 \\
(3.32)\end{array}$ & $\begin{array}{c}8 \\
(7.69)\end{array}$ & $\begin{array}{c}51 \\
(3.32)\end{array}$ & $4(5.88)$ & $\begin{array}{c}51 \\
(3.32)\end{array}$ \\
\hline Unknown & $\begin{array}{c}38 \\
(11.08)\end{array}$ & $\begin{array}{c}177 \\
(11.5)\end{array}$ & $\begin{array}{c}91 \\
(11.6)\end{array}$ & $\begin{array}{c}177 \\
(11.5)\end{array}$ & $\begin{array}{c}38 \\
(10.2)\end{array}$ & $\begin{array}{c}177 \\
(11.5)\end{array}$ & $\begin{array}{c}20 \\
(10.15)\end{array}$ & $\begin{array}{c}177 \\
(11.5)\end{array}$ & $\begin{array}{c}21 \\
(20.2)\end{array}$ & $\begin{array}{c}177 \\
(11.5)\end{array}$ & $\begin{array}{c}8 \\
(11.76)\end{array}$ & $\begin{array}{c}177 \\
(11.5)\end{array}$ \\
\hline Alcohol & $\begin{array}{c}7 \\
(2.04)\end{array}$ & $\begin{array}{c}24 \\
(1.56)\end{array}$ & $\begin{array}{c}20 \\
(2.55)\end{array}$ & $\begin{array}{c}24 \\
(1.56)\end{array}$ & $\begin{array}{c}2 \\
(0.54)\end{array}$ & $\begin{array}{c}24 \\
(1.56)\end{array}$ & $\begin{array}{c}0 \\
(0.00)\end{array}$ & $\begin{array}{c}24 \\
(1.56)\end{array}$ & $\begin{array}{c}0 \\
(0.00)\end{array}$ & $\begin{array}{c}24 \\
(1.56)\end{array}$ & $0(0.00)$ & $\begin{array}{c}24 \\
(1.56)\end{array}$ \\
\hline Contamination & $\begin{array}{c}15 \\
(4.37)\end{array}$ & $\begin{array}{c}109 \\
(7.09)\end{array}$ & $\begin{array}{c}26 \\
(3.32)\end{array}$ & $\begin{array}{c}109 \\
(7.09)\end{array}$ & $\begin{array}{c}45 \\
(12.1)\end{array}$ & $\begin{array}{c}109 \\
(7.09)\end{array}$ & $\begin{array}{c}36 \\
(18.3)\end{array}$ & $\begin{array}{c}109 \\
(7.09)\end{array}$ & $\begin{array}{c}6 \\
(5.77)\end{array}$ & $\begin{array}{c}109 \\
(7.09)\end{array}$ & $9(13.2)$ & $\begin{array}{c}109 \\
(7.09)\end{array}$ \\
\hline Illness & $\begin{array}{r}130 \\
(37.9) \\
\end{array}$ & $\begin{array}{r}568 \\
(36.9) \\
\end{array}$ & $\begin{array}{r}344 \\
(43.9) \\
\end{array}$ & $\begin{array}{r}568 \\
(36.9) \\
\end{array}$ & $\begin{array}{r}99 \\
(26.5) \\
\end{array}$ & $\begin{array}{r}568 \\
(36.9) \\
\end{array}$ & $\begin{array}{r}66 \\
(33.5) \\
\end{array}$ & $\begin{array}{r}568 \\
(36.9) \\
\end{array}$ & $\begin{array}{c}18 \\
(17.3) \\
\end{array}$ & $\begin{array}{r}568 \\
(36.9) \\
\end{array}$ & $11(16.2)$ & $\begin{array}{r}568 \\
(36.9) \\
\end{array}$ \\
\hline
\end{tabular}

Table 7: Associated factors of disability among the study population in Dabat district 


\begin{tabular}{|c|c|c|c|c|}
\hline Variable & $\begin{array}{l}\text { Disability, Yes=n } \\
\text { (\%) }\end{array}$ & COR [95\% CI:] & AOR [95\% CI:] & $\begin{array}{l}\text { AOR P- } \\
\text { value }\end{array}$ \\
\hline Age (in year) & & $\begin{array}{r}1.04\left[\begin{array}{l}1.037 \\
1.042]\end{array}\right.\end{array}$ & $\begin{array}{r}1.04 \\
{[1.03,1.04]}\end{array}$ & $<0.001$ \\
\hline \multicolumn{5}{|l|}{ Gender } \\
\hline Male & $700(1.97)$ & 1.00 & 1.00 & \\
\hline Female & $837(2.30)$ & $2.49[0.23,27.5]$ & $\begin{array}{r}1.06[0.94, \\
1.18] \\
\end{array}$ & 0.362 \\
\hline \multicolumn{5}{|l|}{ Educational attainment } \\
\hline Under age (口7years) & $153(0.78)$ & 1.00 & 1.00 & \\
\hline $\begin{array}{l}\text { Unable to read and } \\
\text { write }\end{array}$ & $971(4.36)$ & $5.74[4.84,6.82]$ & $\begin{array}{r}1.57[1.15, \\
1.15]\end{array}$ & 0.004 \\
\hline Able to read and write & $130(2.95)$ & $3.82[3.02,4.84]$ & $\begin{array}{r}1.10[0.77, \\
1.57]\end{array}$ & 0.588 \\
\hline Grade 1 to 3 & $88(1.08)$ & $1.37[1.06,1.79]$ & $\begin{array}{r}0.64[0.45, \\
0.90]\end{array}$ & 0.01 \\
\hline Grade 4 to 6 & $57(1.27)$ & $1.61[1.19,2.19]$ & $\begin{array}{r}0.58[0.39, \\
0.87]\end{array}$ & 0.009 \\
\hline Grade 7 to 8 & $36(1.55)$ & $1.98[1.38,2.86]$ & $\begin{array}{r}0.69[0.44 \\
1.09]\end{array}$ & 0.112 \\
\hline Grade 9 to 10 & $41(1.32)$ & $1.69[1.19,2.39]$ & $\begin{array}{r}0.60[0.39 \\
0.94]\end{array}$ & 0.025 \\
\hline Grade 11 to 12 & $11(0.95)$ & $1.21[0.65,2.23]$ & $\begin{array}{r}0.35[0.18, \\
0.69]\end{array}$ & 0.002 \\
\hline Above 12 & $15(1.47)$ & $1.88[1.10,3.21]$ & $\begin{array}{r}0.54[0.29 \\
0.99]\end{array}$ & 0.047 \\
\hline Unknown & $35(0.65)$ & $0.81[0.56,1.16]$ & $\begin{array}{r}0.44[0.23 \\
0.84]\end{array}$ & 0.012 \\
\hline \multicolumn{5}{|l|}{ Marital Status } \\
\hline Under age $\square 10$ years & $209(0.79)$ & 1.00 & 1.00 & \\
\hline Married & $664(3.01)$ & $3.89[3.32,4.55]$ & $\begin{array}{r}0.79[0.58, \\
1.07]\end{array}$ & 0.136 \\
\hline Single & $287(1.98)$ & $2.52[2.11,3.02]$ & $\begin{array}{r}1.86[1.39 \\
2.48]\end{array}$ & $<0.001$ \\
\hline Divorced & $104(4.49)$ & $5.89[4.64,7.49]$ & $\begin{array}{r}1.02[0.71 \\
1.46]\end{array}$ & 0.931 \\
\hline Widowed & $176(9.33)$ & $12.9[10.48,15.8]$ & $\begin{array}{r}1.17[0.81 \\
1.69] \\
\end{array}$ & 0.396 \\
\hline Separated & $63(10.21)$ & $14[10.6,19.12]$ & $\begin{array}{r}4.15[2.78, \\
6.19] \\
\end{array}$ & $<0.001$ \\
\hline Unknown & $25(0.61)$ & $0.77[0.51,1.17]$ & $\begin{array}{r}2.88[1.52, \\
5.49] \\
\end{array}$ & 0.001 \\
\hline \multicolumn{5}{|l|}{ Place of Residence } \\
\hline Urban & $367(2.08)$ & 1.00 & 1.00 & \\
\hline Rural & $1174(2.15)$ & $1.26[1.10,1.45]$ & $\begin{array}{r}0.98[0.86, \\
1.12]\end{array}$ & 0.8 \\
\hline
\end{tabular}

\section{Figures}




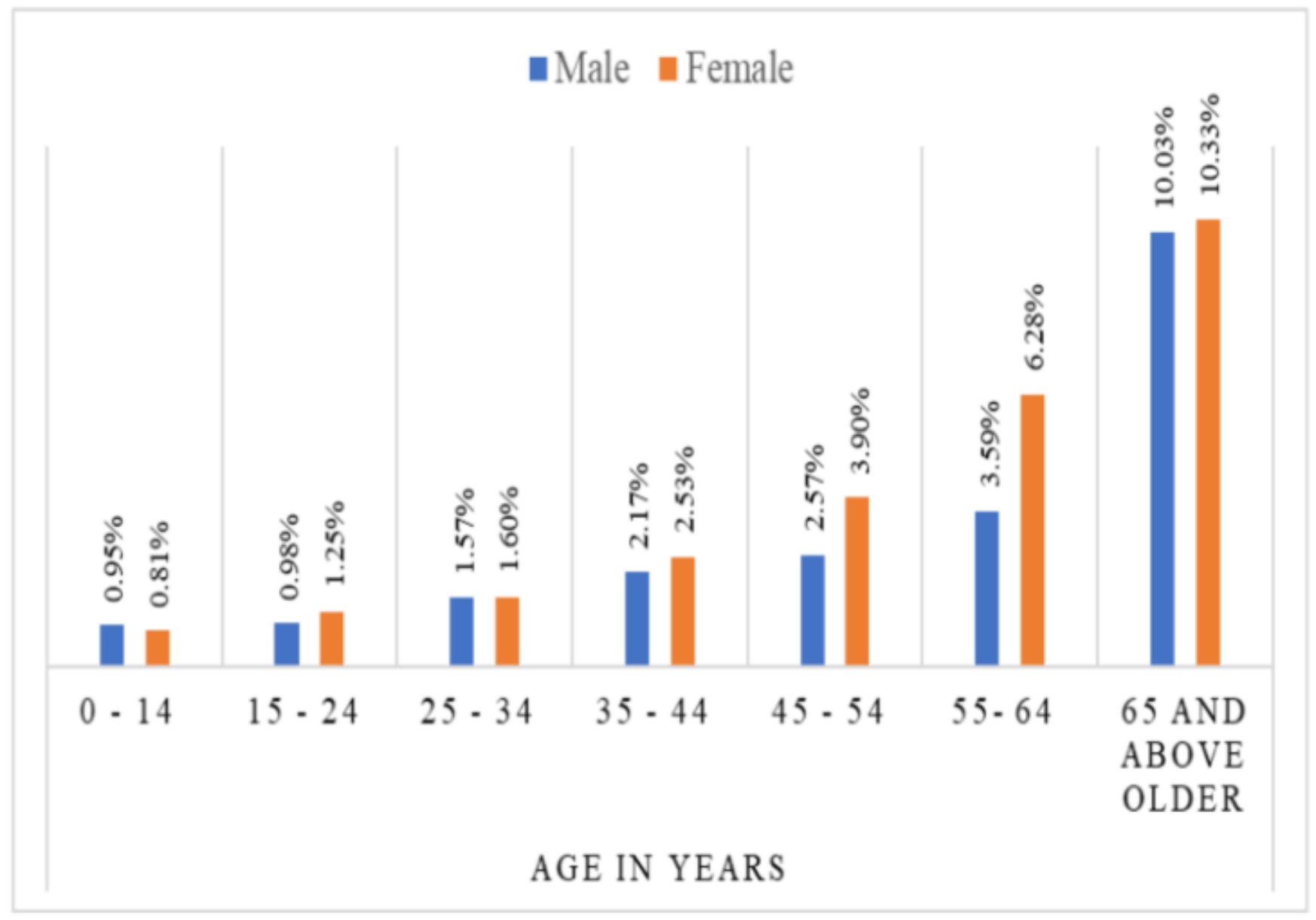

Figure 1

Magnitude of disability by sex and age in Dabat district (Source: Survey 2018) 


\section{Percentage of disability by age and type}

12

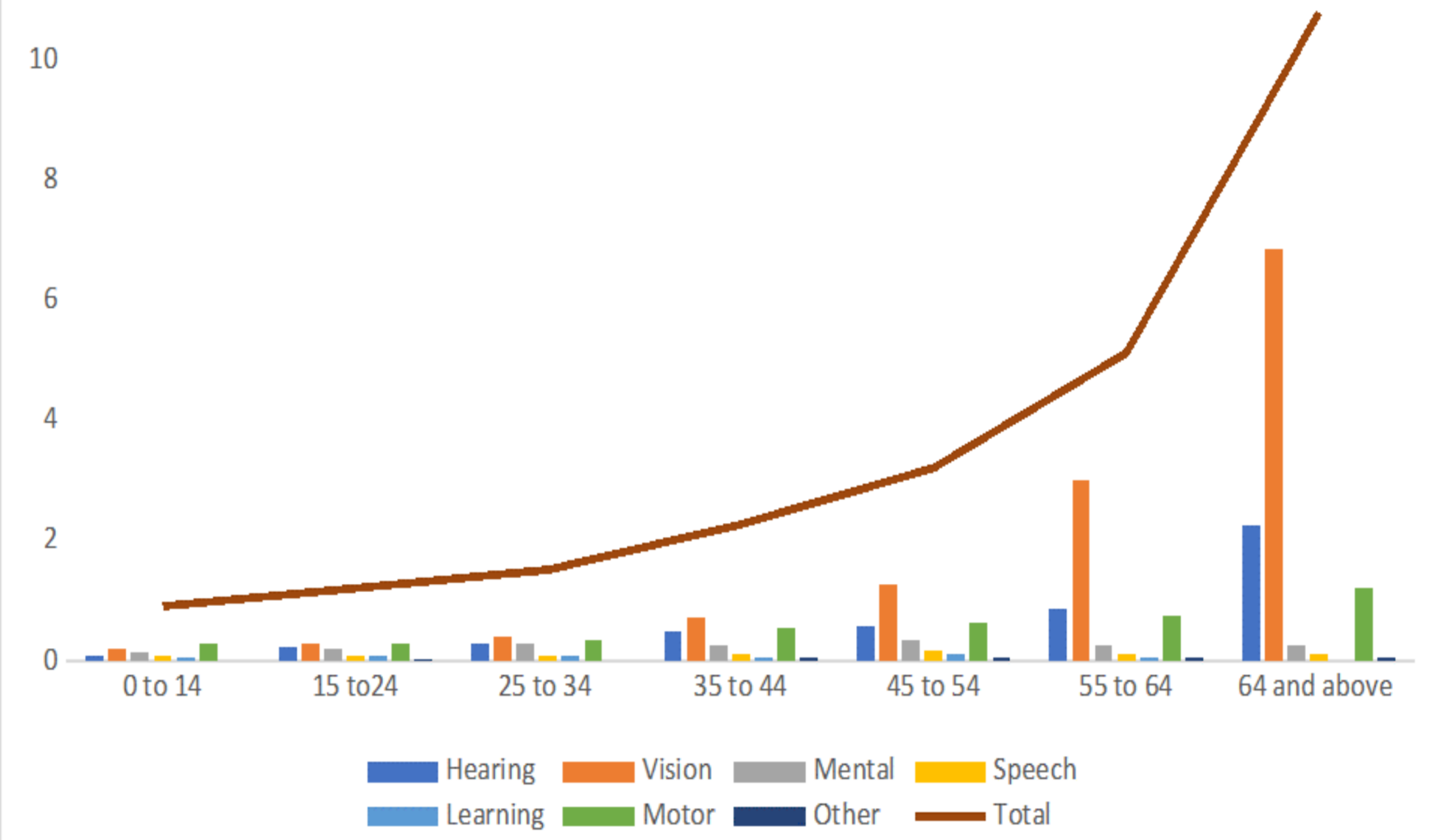

Figure 2

Distribution and type of disability by age among PwDs in Dabat district (Source: Survey 2018) 


\section{Percentage}

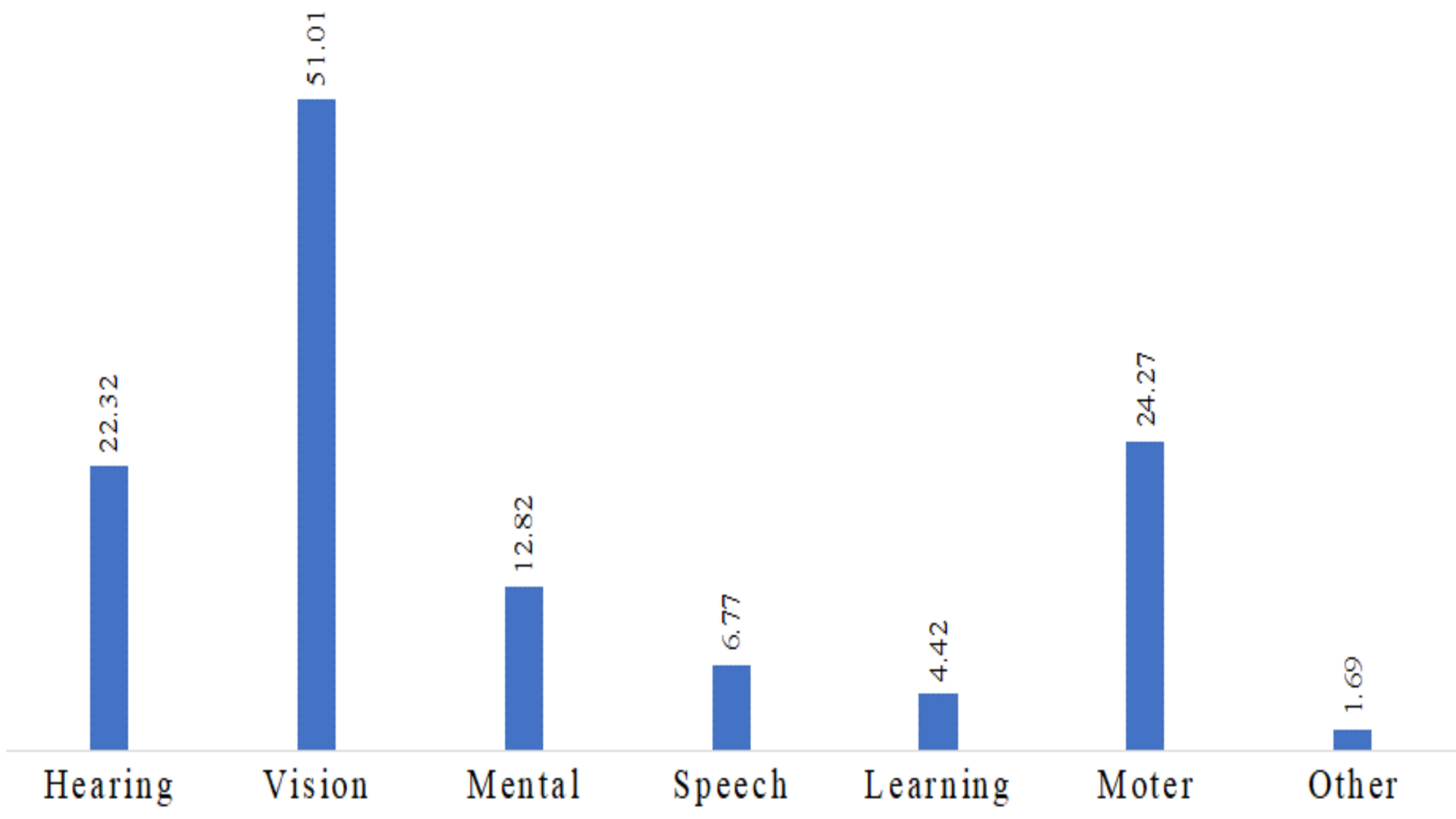

Figure 3

Types of disability among PwDs in Dabat district (Source: Survey 2018) 


\section{Persentage}

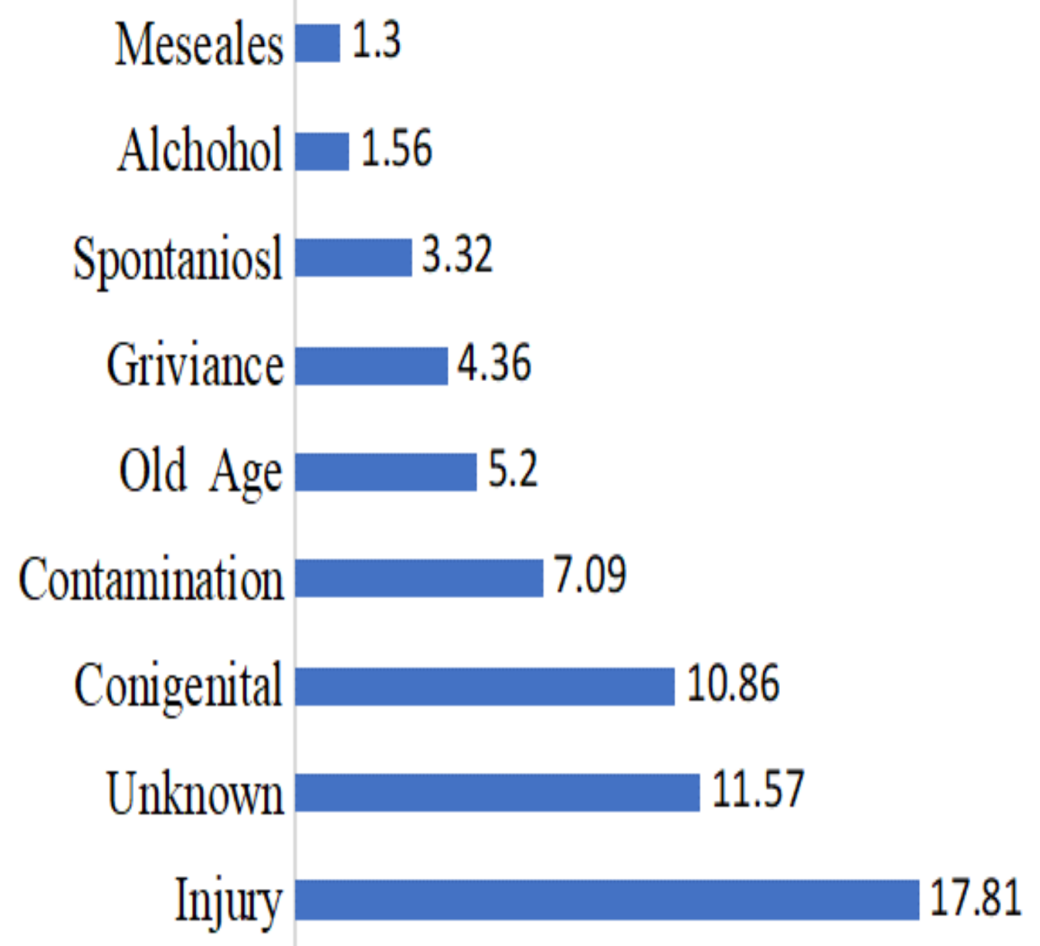

Figure 4

Perceived causes of disability among PwDs in Dabat district (Source: Survey, 2018).

\section{Supplementary Files}

This is a list of supplementary files associated with this preprint. Click to download.

- ChecklistofitemsBMCPHMS2SM.docx 